\section{Schlecht ernährte Nierenkrebs-Patienten haben eine magere Prognose}

Nierenzell-Karzinom-Patienten, die sich vor der Operation in schlechtem Ernährungszustand präsentieren, haben nach der Nephrektomie offenbar deutlich schlechtere Überlebenschancen. Gesamtmortalität und krankheitsspezifische Sterblichkeit fallen signifikant höher aus.

n einer retrospektiven Studie haben USamerikanische Urologen untersucht, welchen Einfluss der präoperative Ernährungszustand auf die Gesamtmortalität von Patienten mit lokoregionärem Nierenzell-Karzinom (RCC) hat. Dazu werteten sie die Daten von 369 Patienten aus, die sich in den Jahren 2003 bis 2008 einer radikalen oder partiellen Nephrektomie unterziehen mussten. Von einem präoperativen Ernährungsdefizit gingen die Wissenschaftler aus, wenn eines von drei Kriterien erfüllt war: Body-Mass-In$\operatorname{dex}<18,5$, Serumalbumin $<3,5 \mathrm{~g} / \mathrm{dl}$ sowie unbeabsichtigter Gewichtsverlust von $\geq 5 \%$ des Ausgangsgewichts in den sechs Monaten vor der Operation.

Insgesamt erfüllten $23 \%$ der Patienten mindestens eine der Bedingungen. 58,5\% von ihnen überlebten die ersten drei Jahre nach dem Eingriff, das errechnete krankheitspezifische Überleben lag bei $80,4 \%$. In der Kontrollgruppe hingegen waren nach drei Jahren noch $85,4 \%$ der Studienteilnehmer am Leben, die krankheitsspezifische Überlebensrate erreichte $94,7 \%(p<0,001)$. Damit erwies sich der Ernährungszustand als signifikanter Prädiktor für die Mortalität.

Die bezüglich Alter, Begleitkrankheiten, Anämie und Ausmaß des Tumorbefalls abgeglichenen Daten flossen anschließend in die Berechnung der Hazard Ratios (HR) ein. Ernährungsdefizite führten bei der Gesamtsterblichkeit (HR 2,41 ) und der krankheitsspezifischen stimmten Zeitspanne eintritt. keit von Nierenkrebspatienten senken können.

Fazit: Defizite in der Ernährung der Patienten gehen laut den Ergebnissen der vorliegenden Untersuchung mit einer deutlich schlechteren Prognose nach operativer Therapie eines lokoregionären Nierenzell-Karzinoms einher. Im retrospektiven Design lässt sich aber nicht beweisen, dass Gewichtszunahme vor dem Eingriff die Überlebensaussichten verbessern könnte. Hierfür wären prospektive Studien nötig. Dr. Robert Bublak gleichskollektiven binnen einer be-

Die Autoren sehen in den Ergebnissen einen Hinweis darauf, wie sich die präoperative Beratung von Patienten verbessern ließe. Sie fordern prospektive Studien, um zu klären, ob ernährungsbezogene Maßnahmen die postoperative Sterblich-

Morgan TM et al. Preoperative Nutritional Status Is an Important Predictor of Survival in Patients Undergoing Surgery for Renal Cell Carcinoma. Eur Urol 2011; 59: 923-8

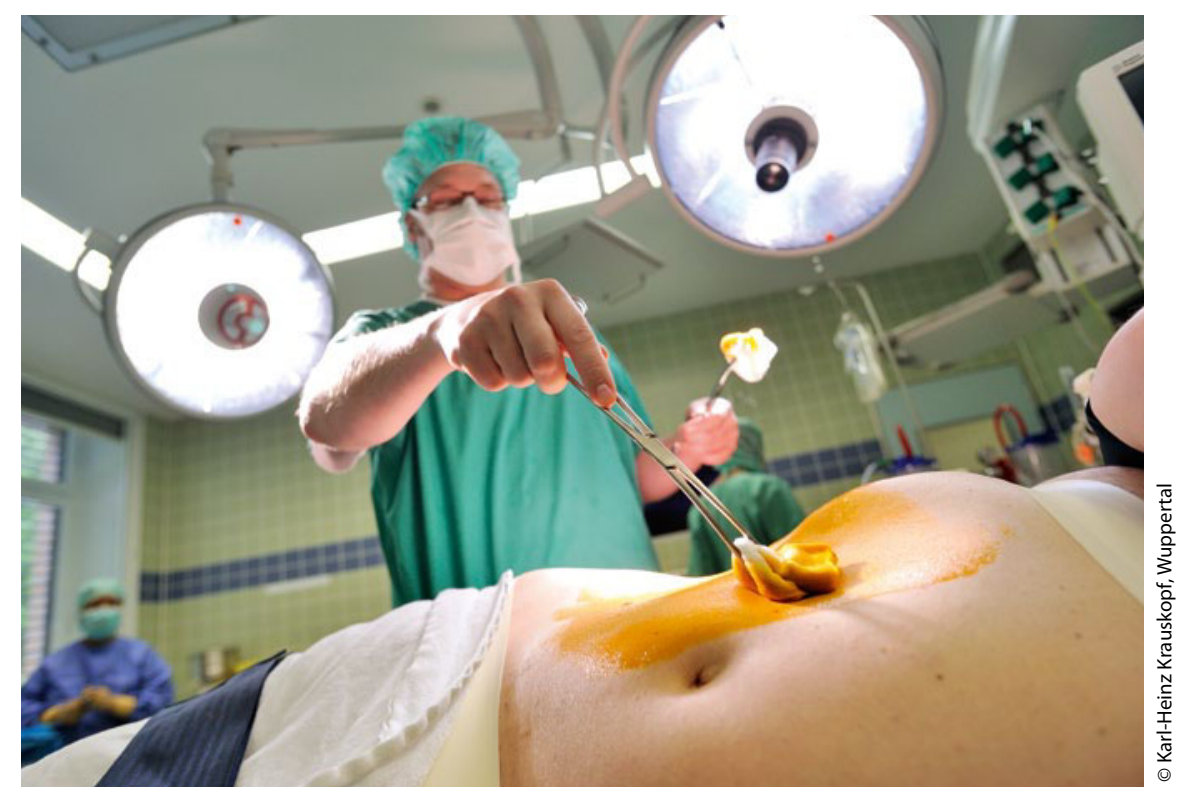

Vorbereitung zur Nephrektomie. Wie lange Nierenkrebs-Patienten nach dem Eingriff überleben, hängt auch von ihrem präoperativen Ernährungszustand ab. 